\title{
Công bố nghiên cứu toàn cảnh phản ứng của Việt Nam trước đại dịch
}

\author{
Nguyễn Phúc Khánh Linh, Hồ Mạnh Toàn \\ Trung tâm ISR, trường Đại học Phenikaa \\ Khoa học \& Phát triên
}

KH\&PT (10-4-2020; https://khoahocphattrien.vn/khoa-hoc/cong-bo-nghien-cuu-toancanh-phan-ung-cua-viet-nam-truoc-dai-dich/20200410114612631p1c160.htm) -- Nghiên cứu phân tích các phản ứng của Chính phủ, phương tiện truyền thông xã hội và báo chí khoa học tại Việt Nam kể từ khi thông tin về dịch viêm phổi lạ tại Trung Quốc xuất hiện cho đến nay như một cách lý giải vi sao Việt Nam có thể ứng phó với COVID-19 hiệu quả.

Ngày 7/4 vừa qua, nghiên cứu Policy Response, Social Media and Science Journalism for the Sustainability of the Public Health System Amid the COVID-19 Outbreak: The Vietnam Lessons (Phản ứng chính sách, mạng xã hội, và báo chí khoa học phục vụ sự bền vững của hệ thống y tế giữa đại dịch COVID-19: Các bài học từ Việt Nam) [1] của Trung tâm Nghiên cứu Xã hội Liên ngành (ISR) thuộc trường Đại học Phenikaa vừa được công bố trên tạp chí Sustainability (IF 2,592; CiteScore 3,01; H-Index 53).

Nghiên cứu tập trung phân tích các phản ứng của Chính phủ, phương tiện truyền thông xã hội và báo chí khoa học tại Việt Nam kể từ khi các thông tin về dịch viêm phổi lạ tại Trung Quốc xuất hiện cho đến nay.

Một công cụ thu thập dữ liệu web do A.I. for Social Data Lab (AISDL) thiết kế và phát triển đã được sử dụng để rà soát và tổ chức các thông tin liên quan đến COVID-19 từ các trang truyền thông chính thức trong khoảng thời gian từ đầu tháng 1/2020 đến ngày $4 / 4 / 2020$. 


\section{Open Access Article}

Policy Response, Social Media and Science Journalism for the Sustainability of the Public Health System Amid the COVID-19 Outbrei The Vietnam Lessons

\footnotetext{
by $($ Viet-Phuong La, $($ Thanh-Hang Pham, Manh-Toan Ho, Minh-Hoang Nguyen, Chanh-Linh P. Nguyen, (Nhu-Trang Vuong, ( Hong-Kong T. Nguyen, ( Trung Tran, Quy Khuc, Manh-Tung Ho and $\mathbb{P}$ Quan-Hoang Vuong Sustainability 2020, 12(7), 2931; https://doi.org/10.3390/su12072931 (registering DOI) - 07 Apr 2020 Abstract Vietnam, with a geographical proximity and a high volume of trade with China, was the firs country to record an outbreak of the new Coronavirus disease (COVID-19), caused by the Severe A Respiratory Syndrome Coronavirus 2 or SARS-CoV-2. While the country was expected [...] Read $m$

$\checkmark$ Show Figures
}



\section{Nghiên cứu toàn cảnh về phản ứng của Việt Nam trước đại dịch COVID-19 trên tạp chí Sustainability.}

Dựa trên 14.952 tin tức thu thập được, nhóm tác giả cho thây tại sao Việt Nam có thể ứng phó với COVID-19 hiệu quả dù là một quốc gia có nguy cơ lây nhiễm cao do vị trí địa lý và mối quan hệ sát với Trung Quốc, nơi dịch bệnh bùng phát đầu tiên.

Ngay từ rất sớm vào đầu tháng Một, khi căn bệnh viêm phổi lạ lây lan tại Trung Quốc Chính phủ Việt Nam đã đưa ra các chỉ thị để ứng phó với dịch bệnh. Theo nghiên cứu, có lẽ ký ức từng đối mặt với các đại dịch lớn trước đây như SARS năm 2003 đã giúp Việt Nam cẩn trọng với COVID-19. Điều này được thể hiện khi các đơn vị truyền thông cũng bám sát và đưa tin liên tục về dịch: kể từ ngày 9/1 đến 15/3, trung bình 127 tin tức về dịch bệnh được đăng tải hàng ngày trên 13 trang báo lớn tại Việt Nam. Nỗ lực ứng phó kịp thời này được củng cố sức mạnh nhờ các nhà khoa học Việt Nam liên tục đưa ra các phân tích, đánh giá tình hình trên truyền thông, tạo ra nguồn thông tin tin cậy trên mạng xã hội. 
Giai đoạn sau này, sự quyết liệt tiếp tục được duy trì nhờ các chính sách cách ly, giãn cách xã hội. Bên cạnh đó, một số bài báo khoa học về các ca bệnh đầu tiên từ Việt Nam cũng tiếp tục mang lại các thông tin quan trọng. Tính tới thời điểm đăng bài, nhóm tác giả tìm thấy 4 bài báo khoa học liên quan đến COVID-19 từ Việt Nam, trong đó 1 bài công bố rất sớm vào ngày $28 / 1$, chỉ khoảng 5 ngày sau ca đầu tiên. Ngoài ra, các nhà nghiên cứu từ hơn 20 viện nghiên cứu và trường đại học cũng tham gia đóng góp, sáng chế kịp thời nước rửa tay sát khuẩn, buồng khử khuẩn, để phục vụ cộng đồng.

Chỉ khoảng 36 giờ sau khi xuất bản, bài nghiên cứu đã có hơn 2.000 lượt truy cập, và 500 lượt download. Hiện nó đang đứng đầu danh sách được đọc nhiều của tạp chí Sustainability.

Với thời gian hạn chế - bắt đầu triển khai từ giữa tháng 3, sau 1 tuần có bản thảo đâu tiên và sau 2 tuần nữa có bản thảo hoàn chỉnh [2] - nhóm nghiên cứu đã rất nỗ lực để đóng góp một trong những nghiên cứu xã hội sớm nhất về COVID-19 từ Việt Nam. Trong lời đề tựa của bài, nhóm nghiên cứu chia sẻ:

"Chúng tôi xin dành tặng công trình nghiên cứu này cho Tổ Quốc của mình, đất nước Việt Nam, cho Chính phủ, và cho người dân Việt, vì tất cả những điều dân tộc chúng ta đã chung tay cùng làm trong cuộc chiến chống COVID-19. Chúng tôi xin bày tỏ sự đồng cảm sâu sắc với những người bị ảnh hưởng bởi dịch bệnh này, và xin gửi sự trân trọng đến các bác sỹ và nhân viên y tế, những người dũng cảm xả thân giúp đỡ các bệnh nhân. Chúng tôi mong rằng giai đoạn khó khăn này cho tất cả chúng ta sẽ sớm qua."

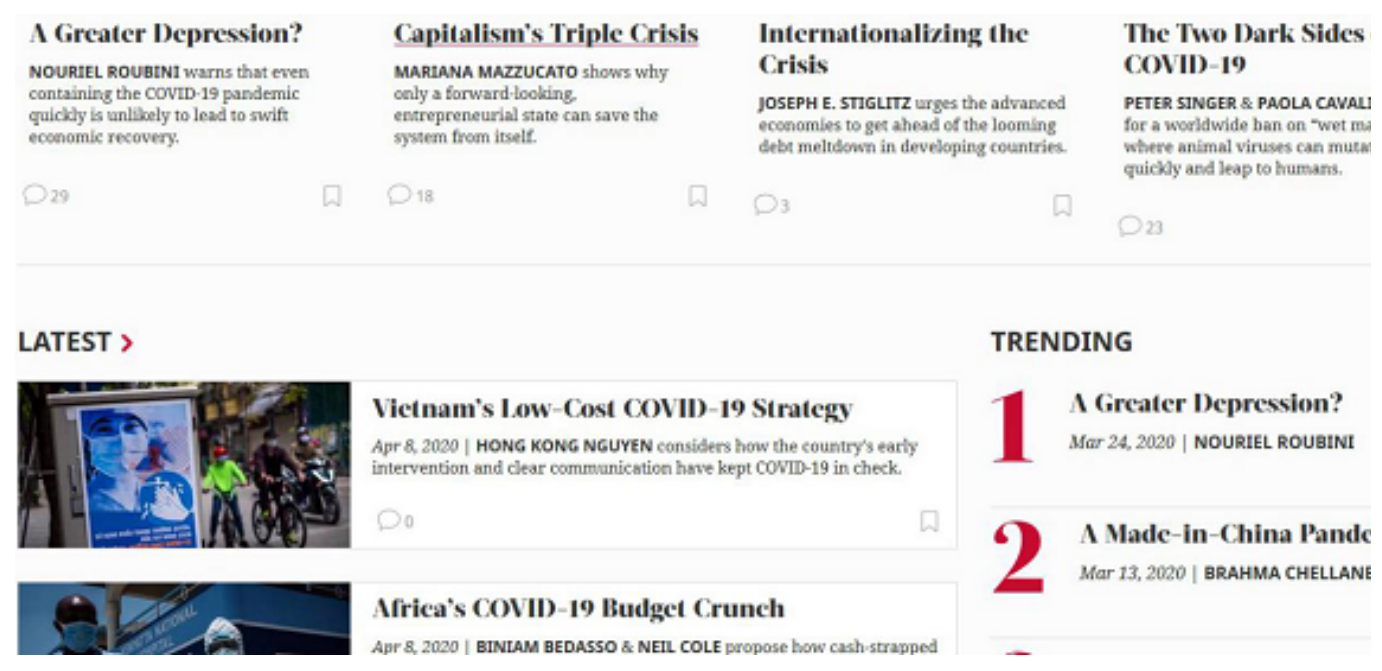

Hình ảnh trang chủ của Project Syndicate có hiện diện bài tiêu điểm về COVID19 từ Việt Nam. Ánh chụp màn hinh ngày 9-4-2020. 
Đặc biệt, ngày 8/4, trang nghiên cứu kinh tế và chính sách nổi tiếng thế giới Project Syndicate đã đăng bài quan điểm (Op Ed) Vietnam's Low-Cost COVID-19 Strategy của tác giả Hong Kong Nguyen [3] với tiêu điểm là nghiên cứu COVID-19 của Trung tâm ISR, tức chỉ một ngày sau khi nghiên cứu được xuất bản trên Sustainability. Bài quan điểm cũng lên tiếng về sự hiệu quả của Việt Nam trong kiểm soát dịch bệnh nhờ các chính sách can thiệp sớm, và việc truyền thông rõ ràng tới công chúng.

\section{Tài liệu tham khảo:}

[1] La VP, Pham TH, Ho MT, Nguyen MH, ..., Vuong QH. (2020). Policy Response, Social Media and Science Journalism for the Sustainability of the Public Health System Amid the COVID-19 Outbreak: The Vietnam Lessons. Sustainability, 12(7), 2931. https://doi.org/10.3390/su12072931.

[2] La VP, Pham TH, Ho TM, ..., Vuong QH. (2020). Policy response, social media and science journalism for the sustainability of the public health system amid COVID19 outbreak: The Vietnam lessons. SocArXiv Preprints,

DOI:10.31235/osf.io/cfw8x.

[3] Nguyen HK. (2020, April 8). Vietnam's Low-Cost COVID-19 Strategy. Project Syndicate; https://www.project-syndicate.org/commentary/vietnam-low-costsuccess-against-covid19-by-hong-kong-nguyen-2020-04 